\title{
(t)
}

\section{O SERVICCO SOCIAL NOS PROGRAMAS DE RESIDÊNCIA EM SAÚDE: RESULTADOS INICIAIS DO MAPEAMENTO DA ABEPSS}

\author{
THE SOCIAL WORK IN PROGRAMS OF RESIDENCE IN \\ HEALTH: INITIAL RESULTS OF ABEPSS MAPPING
}

\section{Marina Monteiro de Castro e Castro'}

\section{RESUMO}

O presente artigo tem por objetivo apresentar os resultados iniciais do mapeamento sobre a inserção do Serviço Social nos Programas de Residência em Saúde. Tal mapeamento, conduzido pela ABEPSS em 2012, foi realizado com vinte e quatro programas inseridos nas regionais leste, centro-oeste e sul 1 e abordou questões referentes ao projeto pedagógico e à organização prática e teórica dos programas, apresentando limites e possibilidades para a formação continuada em saúde. $\mathrm{O}$ estudo demonstrou que os Programas de Residência têm contribuído para qualificar o trabalho desenvolvido nos serviços de saúde, porém é necessário problematizar o contexto de ataque às políticas de saúde e educação que influencia diretamente no direcionamento da formação em saúde.

Palavras-chave: Serviço Social. Saúde. Educação. Residência.

\section{ABSTRACT}

This article aims to present the initial results of the mapping on the insertion of Social Work in Health Residency Programs. Such mapping, conducted by ABEPSS in 2012, was realized with twenty-four programs in the eastern, center-west and south 1 regionals and addressed issues relating to the pedagogical design and to practical and theoretical

1 Professora Assistente da Universidade Federal de Juiz de Fora. Faculdade de Serviço Social. Doutoranda em Serviço Social (ESS/UFRJ). E-mail: marinamccastro@yahoo.com.br. 
organization of programs, presenting limits and possibilities for continuing education in health. The study showed that the Residency Programs have helped to qualify the work developed in health services, but it is necessary to problematize the context of attack on health and education policies that directly influences the direction of health formation.

Keywords: Social Work. Health. Education. Residency.

Submetido em 04/07/2013

Aceito em 20/12/2013

\section{INTRODUÇÃO}

A gestão 2011-2012 da Associação Brasileira de Ensino e Pesquisa em Serviço Social (ABEPSS) teve como uma de suas prioridades o debate em torno da formação em saúde, especialmente no que tange ao direcionamento do processo formativo do Serviço Social nos Programas de Residência.

Para conhecimento e sistematização das experiências existentes, foi proposta a realização de um mapeamento da formação em saúde do Serviço Social nos Programas de Residência, a partir do levantamento de questões sobre o projeto pedagógico dos cursos, as áreas de concentração, os sujeitos envolvidos e a relação formação/diretrizes curriculares do Serviço Social.

A devolutiva desse mapeamento foi realizada por três regionais da ABEPSS: leste, que apresentou a experiência de treze programas; centro-oeste, de três; e regional sul I, que mapeou as residências no estado Rio Grande do Sul, contemplando oito programas.

Para a apresentação de um panorama mais ampliado possível, utilizaram-se, além dos dados do mapeamento, informações levantadas nas Oficinas Regionais e Nacional da ABEPSS e pesquisa via internet dos editais dos programas.

Assim, este artigo visa apresentar a sistematização dos resultados iniciais do mapeamento com o intuito de indicar elementos para se avançar nas análises em torno da inserção do Serviço Social nesses espaços e problematizar o cenário que envolve os Programas de Residência. 


\section{O SERVIÇO SOCIAL NOS PROGRAMAS DE RESIDÊNCIA EM SAÚDE}

As Residências em Saúde constituem-se modalidades de ensino de pós-graduação lato sensu, sob a forma de curso de especialização caracterizado por ensino em serviço, com carga horária de sessenta horas semanais e duração mínima de dois anos. Podem se organizar na modalidade de área específica e multiprofissional, contemplando no mínimo três profissões da saúde.

No mapeamento realizado, identificou-se que o Serviço Social encontra-se inserido principalmente nos programas de modalidade multiprofissional, criados a partir de 2009. Esse fato se explica pelo incentivo do Ministério da Saúde, no final dos anos 2000, para a abertura de programas multiprofissionais, com o discurso da necessidade de provocar mudanças na formação em saúde e construir um trabalho interdisciplinar e coletivo, atento aos princípios e diretrizes do SUS, que qualifique as ações em saúde.

Em relação aos programas em Área Profissional, localizaram-se apenas dois. Estes foram criados há mais de quinze anos e encontram-se inseridos na área de abrangência da regional leste, respectivamente nos Hospitais Universitários (HU) da Universidade do Estado do Rio de Janeiro (UERJ) e da Universidade Federal de Juiz de Fora (UFJF).

Os programas estão inscritos em diferentes áreas de concentração, porém há uma maior inserção do Serviço Social nos programas com foco na Saúde da Criança/Saúde do Adolescente, seguidos por Saúde do Adulto e Saúde Mental, estando em acordo com as áreas enfatizadas como prioritárias pelo Ministério da Saúde.

O número de vagas ofertadas pelos programas para assistentes sociais gira em torno de cento e cinco vagas/ano. Esse dado expressa um número significativo de profissionais inseridos nos serviços públicos de saúde, já que contempla o mesmo número no segundo ano de residência. Os estados com maior oferta de vagas são Rio de Janeiro e Rio Grande do Sul. Os programas envolvem ainda mais de cem profissionais assistentes sociais que realizam a função de tutores e preceptores dos programas. 
No que concerne ao cenário de prática, grande parte dos programas é desenvolvida no espaço hospitalar e uma pequena parcela na Estratégia Saúde da Família (ESF) e no setor secundário. É importante destacar que alguns programas enfatizam o espaço hospitalar, mas realizam intercâmbio com a atenção básica e secundária; e os programas que têm como eixo a Saúde Mental realizam suas atividades nos serviços especializados (ex.: Centro de Atenção Psicossocial - CAP).

Outro elemento essencial referente ao cenário de prática é a natureza dos hospitais onde se desenvolvem as atividades dos programas: grande parte diz respeito a Hospitais Universitários.

Indica-se que a centralidade de desenvolvimento dos programas em hospitais e, especialmente, em Hospitais Universitários pode estar vinculada a duas questões. A primeira diz respeito a não inserção do assistente social na equipe básica do Programa de Saúde da Família, o que traz limitações para a criação de Residências nesse espaço, já que há a necessidade do preceptor de serviço.

A segunda questão trata do incentivo à criação de Programas de Residência nos HUs a partir do Programa de Reestruturação dos Hospitais de ensino (REHUF), instituído em 2010 pelo Decreto 7.082. Tal decreto dispõe que os HUs devem implementar a Residência multiprofissional nas áreas estratégicas para o SUS, estimulando o trabalho em equipe multiprofissional, o que contribui para a qualificação dos recursos humanos especializados com vistas a garantir a assistência integral à saúde.

No entanto, o contexto de expansão dos Programas de Residência se desenvolve no mesmo cenário de ataque à política pública de saúde, de precarização dos serviços e de falta de condições de trabalho, impactando diretamente na formação em saúde e na qualidade dos serviços prestados.

Como elementos caracterizadores desse processo, foram destacados no mapeamento o subfinanciamento e o ataque às políticas públicas de educação e de saúde, que trazem desdobramentos para a direção social do processo formativo e para a 
organização das profissões, que passam a se pautar em uma lógica privatista e produtivista, secundarizando o ensino e a pesquisa.

A ausência de condições de trabalho, o sucateamento das instituições e a limitação de recursos humanos também foram destacados como elementos que trazem dificuldades/desafios para a garantia de uma formação de qualidade e a defesa dos princípios e diretrizes do SUS. A falta de espaço físico, por exemplo, impacta no desenvolvimento de atividades grupais de educação em saúde, reuniões de equipe e atendimentos individuais, não cumprindo, muitas vezes, o que está definido na Resolução 493/2006 do Conselho Federal de Serviço Social (CFESS), que dispõe sobre as condições éticas e técnicas do exercício profissional do assistente social.

Em relação aos recursos humanos, viu-se que o reduzido quadro de profissionais, tanto no espaço hospitalar como na atenção secundária e básica, tem trazido claras dificuldades para que estes se disponibilizem para assumir a preceptoria da Residência. Outra questão é a própria fragmentação do trabalho profissional em alguns espaços onde o assistente social atende a vários territórios e não desenvolve um trabalho contínuo nas unidades de saúde.

A forma de contratação dos profissionais é outro destaque importante, uma vez que parte dos trabalhadores da saúde possui contratos precarizados, flexibilizados, sem garantia de direitos trabalhistas.

Para os HUs, há ainda o risco da entrada da Empresa Brasileira de Serviços Hospitalares (EBSERH), de sua lógica gerencial de mercado e da sua inclinação para mensurar procedimentos da assistência em saúde, desconsiderando o tripé ensino, pesquisa e extensão. A implantação da empresa representa um ataque direto aos serviços do SUS, ao indicar a mercantilização dos serviços públicos de saúde ofertados pelos HUs.

Um elemento pontuado no mapeamento por alguns programas diz respeito ao fato de que esse cenário de ataque às políticas de saúde é debatido no âmbito da Residência e que, em particular, a proposta da EBSERH tem sido objeto de debates, 
atos e posicionamentos políticos contrários aos do Serviço Social nos HUs.

Entende-se que o quadro exposto influencia diretamente no processo formativo desencadeado pelas Residências, mas traz implicações ainda maiores para o acesso da população aos serviços públicos de saúde e para o desenvolvimento de serviços qualificados que visem à assistência integral à saúde.

\section{PROJETOS PEDAGÓGICOS DOS PROGRAMAS DE RESIDÊNCIA E SERVIÇO SOCIAL}

O projeto pedagógico dos Programas de Residência, de acordo com a legislação vigente (Resolução n. 2 do Conselho Nacional de Residência Multiprofissional em Saúde - CNRMS de 2012), deve ser orientado por núcleos específicos dos saberes e práticas próprias a cada profissão, sendo direcionado por uma atuação multiprofissional e interdisciplinar e organizado por atividades teóricas, práticas e teórico-práticas.

O projeto pedagógico deve conter as estratégias pedagógicas utilizadas, as quais devem usar e promover cenários de aprendizagem a partir de linhas de cuidado nas redes de atenção à saúde, de modo a garantir a formação fundamentada na atenção integral, multiprofissional e interdisciplinar.

Dessa maneira, os projetos pedagógicos dos programas devem prever metodologias de integração de saberes e práticas que permitam construir competências compartilhadas, tendo em vista a necessidade de mudanças nos processos de formação, de atenção e de gestão na saúde (BRASIL, 2012).

Por sua vez, o Serviço Social tem posto em suas diretrizes curriculares que uma formação de qualidade deve capacitar o(a) assistente social para:

1. Apreensão crítica do processo histórico como totalidade;

2. Investigação sobre a formação histórica e os processos sociais contemporâneos que conformam a sociedade brasileira, no sentido de apreender as particularidades da constituição e desenvolvimento do capitalismo e do Serviço Social no país; 
3. Apreensão do significado social da profissão, desvelando as possibilidades de ação contidas na realidade;

4. Apreensão das demandas - consolidadas e emergentes - postas ao Serviço Social via mercado de trabalho, visando formular respostas profissionais que potenciem o enfrentamento da questão social, considerando as novas articulações entre público e privado;

5. Exercício profissional cumprindo as competências e atribuições previstas na Legislação Profissional em vigor (ABEPSS, 1997, p. 7-8).

A ABEPSS, na condição de entidade organizativa que tem como finalidade coordenar e avaliar a política de formação profissional na área de Serviço Social, defende a formação profissional como um processo permanente de qualificação e atualização para o deciframento do cotidiano da realidade social, com vistas a evitar a fragmentação e a imediaticidade de conteúdos descolados do projeto de formação profissional que possam contribuir para a proliferação e recorrência do pensamento conservador no interior da profissão (CFESS, 2012).

A política de educação permanente do conjunto CFESS/ CRESS aponta, por sua vez, que a educação permanente no Serviço Social pressupõe a afirmação do projeto ético-político profissional, articulando uma dupla dimensão: as condições macrossocietárias, que estabelecem o terreno sócio-histórico em que se exerce a profissão, seus limites e possibilidades; e as respostas de caráter ético-político e técnico-operativo dos(as) agentes profissionais a esse contexto, apoiadas nos fundamentos históricos, teóricos e metodológicos do Serviço Social (CFESS, 2012).

Tendo em vista os direcionamentos expostos para a apropriação da relação entre os projetos pedagógicos dos Programas de Residência, o projeto formativo e as diretrizes curriculares do Serviço Social, enfatizaram-se no mapeamento três eixos principais: a articulação da formação generalista com o debate da política pública de saúde; a articulação com os demais eixos das diretrizes; e o debate em torno da reforma sanitária.

No mapeamento, identificou-se que os programas contemplam em seus projetos pedagógicos a afirmação dos 
preceitos do SUS e que grande parte foi construída com a participação do Serviço Social, sendo indicada como essencial para garantir nos projetos pedagógicos os princípios e as diretrizes do SUS, conectados com as necessidades de saúde da população. No entanto, também foi enfatizado que, em alguns espaços, os projetos foram construídos para atender à demanda ministerial de instalação de Programas de Residência multiprofissionais, gerando tensões e divergências quanto aos propósitos da Residência.

No que tange à inserção/articulação dos projetos pedagógicos com os parâmetros curriculares de formação do Serviço Social, identificou-se que em alguns projetos foi possível garanti-los (não sem embates) nos eixos específicos do Serviço Social. Em outros projetos, essa vinculação não é expressa.

Os coordenadores do Serviço Social nos Programas de Residência têm realizado o esforço de garantir o direcionamento das diretrizes curriculares, principalmente nas atividades práticas e teóricas do eixo específico, uma vez que possuem autonomia na organização dessas atividades. A formação generalista do Serviço Social foi destacada como importante, pois possibilita um olhar ampliado e crítico sobre as questões relativas ao campo da saúde e a articulação com as demais políticas públicas.

No desenvolvimento das atividades teórico-práticas, foi colocada, apenas por uma pequena parcela, a referência aos parâmetros para a atuação do Serviço Social na saúde (publicado pelo CFESS em 2010) como suporte para o debate/direcionamento de uma ação de qualidade, comprometida com a população e com os serviços públicos de saúde.

Como dificuldade para a articulação da formação generalista com a política de saúde, indicou-se a necessidade de melhor apropriação de habilidades e competências profissionais para o desenvolvimento de uma postura investigativa (ex.: conhecer a população usuária) e propositiva nos espaços sócio-ocupacionais da saúde. 
O processo de ataque às políticas públicas de saúde é posto como elemento que também precisa ser problematizado, devendo esse cenário permitir ao assistente social participar de lutas, resistências e propostas no âmbito da política pública de saúde.

No que concerne à articulação com os demais eixos das diretrizes curriculares do Serviço Social, percebeu-se que estes são essencialmente possíveis de se garantir no eixo específico do Serviço Social. Neste, a grande parte dos programas aborda a relação teoria/prática, o projeto ético-político profissional e sua interface com a saúde, o trabalho em equipe e a interdisciplinaridade. Levantou-se também a preocupação de garantir nos espaços específicos da área a articulação das dimensões profissionais e a capacitação teórico-metodológica, ético-política e técnico-operativa.

No que diz respeito ao debate em torno da reforma sanitária, a totalidade dos programas compreende que essa discussão é central para o entendimento da saúde enquanto direito e para a afirmação de uma política pública de saúde que atenda às necessidades da população. Encontraram-se afirmações que colocam que, na formação, é o debate da reforma sanitária que possibilita a articulação de construção de novas práticas pedagógicas, currículos mais integrados, entre trabalho e formação, permitindo um diálogo entre o ensino e as modificações na área da saúde.

O debate teórico sobre a política de saúde e a reforma sanitária é garantido prioritariamente no módulo teórico transversal. Nos momentos específicos da área, esse debate ocorre através do levantamento das possibilidades de efetivação dos pressupostos da reforma sanitária e do SUS no cotidiano de trabalho.

Temas como a concepção de saúde e doença, o processo saúde-doença e suas determinações, a constituição de redes de assistência, o corte neoliberal nas atuais políticas sociais (privatização, subfinanciamento, propostas gerenciais de mercado para as unidades de saúde pública etc.) são colocados como expressões do debate da reforma sanitária no âmbito da formação do Serviço Social. 
Apesar de se identificar a garantia do debate da reforma sanitária no eixo específico do Serviço Social, apontaram-se dificuldades de garantir essa discussão transversalmente. Alguns programas destacaram que no eixo transversal é perceptível um debate/polêmica entre as áreas sobre as possibilidades de se criarem estratégias reais para a efetivação das propostas do SUS.

Os desafios para se garantir o direcionamento dado pelas diretrizes curriculares do Serviço Social foram elencados da seguinte forma: convergência de ofertas de dispositivos de aprendizagem na residência articulados aos núcleos de fundamentação da formação profissional (teórico-metodológicos da vida social, sócio-histórica, da sociedade brasileira e do trabalho profissional); operacionalização dos conteúdos propostos pelas diretrizes do Serviço Social; mediações dentro do terreno das contradições e complexidades da nossa sociedade, que devem ser estimuladas, pensadas e propostas pelos envolvidos, superando a formação técnico-instrumental.

Dessa forma, percebe-se que é necessário avançar na consolidação e implementação do projeto profissional no âmbito das Residências; fomentar o processo de investigação e a capacitação continuada; articular com a sociedade e os movimentos sociais para o enfrentamento da privatização da política de saúde; reforçar e garantir a articulação do tripé ensino, pesquisa e extensão nos Programas de Residência.

\section{ORGANIZAÇÃO PRÁTICA E TEÓRICA DO SERVIÇO SOCIAL NOS PROGRAMAS DE RESIDÊNCIA}

A organização prática e teórica dos Programas de Residência deve contemplar um eixo integrador transversal de saberes, comum a todas as profissões envolvidas; um ou mais eixos integradores da área de concentração do programa; e eixos correspondentes aos núcleos de saberes de cada profissão, de forma a preservar a identidade profissional (BRASIL, 2012).

A carga horária de 60 horas semanais deve ser direcionada por seus eixos nas atividades teóricas, práticas e teórico-práticas, de modo a garantir o ensino em serviço. 
No mapeamento, verificou-se que, de uma forma geral, a carga horária é distribuída conforme as determinações do CNRMS. Porém, são notórios nos relatos a ênfase nas atividades assistenciais e o desenvolvimento de atividades que não garantem o tripé ensino, pesquisa e extensão.

Parte dos programas apontou dificuldades para a inserção dos plantões na organização das atividades. Em algumas instituições, o plantão do Serviço Social não ocorre por não haver atuação do assistente social nesse espaço. Nesses casos, os assistentes sociais residentes realizam atividades substitutivas, gerando tensionamentos com as outras áreas em torno do cumprimento da carga horária.

Identificou-se também que, quando ocorre a realização do plantão, há dificuldades de incorporar atividades que rompam com o modelo tradicional de plantão e que imprimam um direcionamento para além das demandas imediatas, dos encaminhamentos, ultrapassando o foco na doença.

No que se refere à inserção da participação nos espaços de controle social na distribuição da carga horária, percebeu-se que grande parte dos programas não prioriza esse espaço.

Compreende-se que o processo de intervenção junto aos espaços de controle social, dentre eles a inserção nos conselhos de saúde, deve ser central no processo formativo das Residências, pois é um espaço de lutas entre interesses contraditórios que expressam diferentes projetos societários e distintas direções para a política de saúde. "O segmento que representa as classes subalternas pode interferir para que o fundo público não seja mercantilizado" (CORREIA, 2006, p. 127), contribuindo para que os recursos sejam gastos com o atendimento de necessidades reais da população e "não fiquem à mercê dos interesses clientelistas, privatistas e/ou de currais eleitorais" (CORREIA, 2006, p. 135).

Em relação à participação dos assistentes sociais residentes nos processos de supervisão de estágio, identificou-se que grande parte dos residentes não assume essa atribuição. Há ainda programas em que os residentes apoiam o processo de aprendizagem 
via estágio, sem se constituírem formalmente como supervisores de campo, ou interagirem com os estagiários em disciplinas comuns e estudos de caso. A interação com o graduando ocorre também através de projetos de extensão.

Destacou-se no mapeamento a necessidade de debater a carga horária de 60 horas, uma vez que a categoria defende a jornada de 30 horas para os assistentes sociais (e todos trabalhadores) e a legislação trabalhista coloca que a jornada deve ser, no máximo, de 44 horas de trabalho.

No que concerne à articulação do Serviço Social com a equipe multiprofissional, percebeu-se um avanço, na medida em que há uma maior interlocução nas atividades, seja no cotidiano da prática, seja nos espaços coletivos, para a discussão das diretrizes dos programas. No entanto, existem ainda dificuldades no estabelecimento da relação multiprofissional e interdisciplinar de diversas ordens: diferenças na compreensão acerca do que é a Residência, do papel dos residentes nos serviços e dos pressupostos da formação em saúde; resistência dos defensores do modelo médico hegemônico em realizar atividades multiprofissionais; e dificuldades em articular o campo específico com o comum, sem que haja a supremacia de uma profissão sobre a outra.

Em referência à organização dos módulos teóricos, verificou-se que no conjunto dos programas há um maior conteúdo destinado à discussão acerca da área da saúde, das especialidades médicas e de temas afins e ao debate do Serviço Social. Nas disciplinas teóricas específicas, são inclusos também temas transversais à atuação da área, sendo dada pouca ênfase ao debate específico dos fundamentos do Serviço Social e sua interlocução com a área da saúde.

Em todos os programas que responderam ao mapeamento, o residente realiza o Trabalho de Conclusão de Curso/Residência. Porém, nenhum deles disponibiliza de forma on-line os trabalhos.

No eixo sobre as estratégias pedagógicas utilizadas, observou-se que os programas se utilizam de estratégias diversas. Para os módulos teóricos/teórico-práticos, há aulas 
expositivas, encontros multiprofissionais, seminário integrador, mesa-redonda, clínica ampliada, discussão de caso clínico, fórum de debate via EaD, teleconferências, debates sobre filmes, grupos de estudos/sessões científicas, oficinas temáticas.

Na interlocução com as atividades práticas, há visita orientada, recepção integrada, diário reflexivo, orientações individuais e coletivas, reunião de equipe, round profissional/visitas multiprofissionais, construção de plano terapêutico/cuidado em equipe, supervisão clínico-institucional, planejamento coletivo e elaboração de diagnóstico situacional. Ocorrem ainda articulação com projetos de extensão, participação em eventos e incentivo à pesquisa.

Para o desenvolvimento dos Programas de Residência, pressupõe-se a existência de uma articulação direta entre instituição formadora e serviços no planejamento/efetivação/avaliação das atividades teóricas/teórico-práticas/práticas.

No que tange a essa articulação, foi visto que, de uma forma geral, há diversos desafios que precisam ser enfrentados. Algumas situações preocupantes se referem às dificuldades de relação entre instituição de ensino e serviço, que gera a necessidade de o preceptor assumir também a função da tutoria, havendo, em outras situações, dificuldades na efetivação da carga teórica. A não articulação da instituição de ensino/serviço incide, assim, na organização de disciplinas e planos de trabalho conjuntos pelo Serviço Social.

Entre os desafios colocados pelas instituições de ensino para legitimação/avanço/debate em torno dos Programas de Residência estão a necessidade de reconhecimento da pós lato sensu e a institucionalização dos programas, uma vez que estes são secundarizados devido à priorização da pós-graduação stricto sensu; a necessidade de reconhecimento e aprovação dos programas nos cursos de Serviço Social, com definição de atividades e atribuição de carga horária docente; o número restrito de docentes interessados em ser tutores do programa; e as dificuldades de interlocução com o serviço. 
Para os serviços, os desafios englobam a necessidade de maior integração entre tutoria/preceptoria; a realização de planejamento e avaliação conjuntos; a ampliação de quadros profissionais nos serviços de saúde; e a precarização das condições de trabalho.

A não designação de carga horária para tutores e preceptores participarem de espaços de articulação e o número reduzido de profissionais nos cenários de prática inviabilizam muitas vezes a saída dos profissionais para os encontros que envolvem a participação do Serviço Social nos programas.

Assim, os profissionais que atuam na Residência apresentaram no mapeamento que, muitas vezes, são penalizados pelo fato de a carga horária dedicada à Residência não ser considerada na organização de suas atividades, uma vez que é vista pelas chefias como um "trabalho extra".

Essas questões têm rebatimentos diretos na relação entre tutor, preceptor e residente. Apesar de ser possível observar que há uma articulação entre esses três segmentos, pôde ser visto que esta ainda ocorre de forma frágil, sem planejamento ou organização coletiva.

Nesse sentido, indica-se a importância da articulação ensino/ serviço para um processo formativo que garanta uma formação e um exercício profissional de qualidade, comprometido com a população usuária dos serviços públicos de saúde.

\section{FORMAÇÃO EM SAÚDE: LACUNAS E FORMAS DE SUPERAÇÃO}

O último item do mapeamento tratou do debate sobre a formação em saúde, principalmente no que concerne às lacunas identificadas a partir das experiências dos Programas de Residência e às possíveis propostas de superação.

Dentre as lacunas apontadas, foram identificadas questões que tratam do processo formativo na graduação, formação multiprofissional/interdisciplinar e organização/desenvolvimento dos programas.

Em referência à formação na graduação, foi posto que as disciplinas sobre saúde oferecidas são insuficientes para qualificar 
uma maturação teórico-metodológica, ético-política e técnico-operativa que possibilite uma interpretação e intervenção sobre as configurações das expressões da questão social vividas pela população no âmbito da saúde. Dessa forma, muitos assistentes sociais chegam à Residência com pouco entendimento acerca do SUS e da reforma sanitária.

Nessa perspectiva, o discente, em seu processo de educação continuada (Residência), sente dificuldades quando é chamado para atuar em uma relação entre ensino e trabalho.

Indicou-se ainda que o ensino na graduação encontra-se centrado em conteúdos muitas vezes desconectados dos núcleos temáticos das diretrizes curriculares, da relação entre ensino, pesquisa e extensão. Essa realidade é encontrada principalmente nos residentes formados em cursos privados. A maior lacuna indicada está no âmbito da dimensão técnico-operativa.

Dessa forma, é necessário qualificar o processo político-pedagógico de aprendizagem na graduação e construir um aprendizado sobre saúde que problematize as políticas no atual contexto nacional e local. Deve-se ainda ofertar disciplinas que tenham um trato voltado para a intervenção profissional, possibilitando ao discente "vivenciar" o tripé ensino/pesquisa/ extensão na saúde. Os parâmetros de atuação dos assistentes sociais na saúde devem ser utilizados como respaldo nos debates teórico-práticos.

Foi problematizado ainda que na graduação a interdisciplinaridade não se efetiva no cotidiano docente e das disciplinas ministradas. Assim, os saberes são "passados" de forma fragmentada, o que repercute de maneira significativa no modo como o residente irá se inserir nas equipes multiprofissionais. Há também a formação diferenciada entre as áreas de atuação, gerando uma disputa por conhecimento e espaço a partir dos diferentes modos de entender e produzir a saúde.

Há um descompasso entre a formação e o enfoque na graduação e na pós-graduação (Residência) em termos de proposta de atuação (disciplinar $X$ multidisciplinar, multiprofissional $X$ 
interdisciplinar, privado $\mathrm{X}$ público, atendimento individual $\mathrm{X}$ atendimento em equipe).

As lacunas em torno da organização/desenvolvimento apontam para as dificuldades na liberação das atividades de assistência para a realização das atividades de ensino, para a falta de educação permanente em saúde para os preceptores e para a necessidade constante do diálogo entre coordenadores/docentes/preceptores das áreas específicas com as demais categorias profissionais no processo de organização das práticas integradas e dos conteúdos teóricos dos eixos transversais.

Destacou-se ainda o impacto trazido com a Resolução n. 2, de 13 de abril/2012, que dispõe sobre a necessidade de titulação mínima de mestrado para os preceptores/tutores que orientam e avaliam os trabalhos de conclusão do programa de Residência e o fomento ao mestrado profissionalizante.

Como propostas de superação, apontaram-se: a aproximação da academia com os serviços deveria ser uma estratégia importante para uma formação voltada para a práxis mais efetiva pelo Serviço Social; a abertura de um maior espaço de discussão e o aprofundamento da prática exercida pelos assistentes sociais na formação; a definição de carga horária para o ensino e a capacitação permanente, com reconhecimento institucional; a oferta de oficinas e o intercâmbio entre as unidades assistenciais da rede de serviços de saúde.

\section{CONSIDERAÇÕES FINAIS}

Os resultados iniciais do mapeamento dos Programas de Residência proposto pela ABEPSS indicam importantes elementos para se pensar a inserção do Serviço Social nesses espaços e seu processo formativo.

É notório que a Residência tem contribuído para qualificar o trabalho desenvolvido nos serviços de saúde e a construção do trabalho interdisciplinar. No entanto, a discussão acerca da Residência alerta para a necessidade de pensar a formação dos trabalhadores em saúde de forma geral, problematizar o entendimento sobre saúde e trabalho e refletir acerca dos impactos que o 
direcionamento mercadológico às políticas de saúde tem gerado nas instituições e no próprio processo formativo da Residência.

Nesse sentido, diversas questões foram levantadas pelo conjunto dos programas que responderam ao mapeamento como sendo necessárias e urgentes para o Serviço Social pensar coletivamente:

- Refletir sobre as condições de trabalho do assistente social e seu reflexo no desenvolvimento da Residência;

- Problematizar as condições de implementação dos programas, o acúmulo de funções e a carga horária de profissionais para preceptoria/tutoria e a não contratação de novos profissionais;

- Definir o entendimento sobre as atribuições do residente/tutor/ preceptor e as competências da instituição formadora e do serviço;

- Debater o espaço da docência e da preceptoria na Residência;

- Problematizar o papel do residente: aluno ou profissional em formação? Qual a sua autonomia profissional?

- Pensar na gestão dos programas: devemos considerar a questão da dedicação exclusiva à Residência?

- Necessidade de capacitação dos tutores e preceptores para além dos modelos do Ministério da Saúde;

- Construir um conceito de multiprofissionalidade e interdisciplinaridade para o trabalho em saúde conectado ao debate da profissão;

- Entender que a interdisciplinaridade que se busca construir no SUS não depende apenas da Residência;

- Problematizar a carga horária de 60 horas dos residentes e debater a respeito do adoecimento dos residentes;

- Educação em saúde ainda é secundarizada nas atividades da Residência. Há uma valorização do atendimento individual em detrimento de outras formas de atendimento coletivas;

- Do ponto de vista da fiscalização, o que implica a proposta de aulas conjuntas, estudos de caso conjuntos?

- Em relação à supervisão de estágio: o residente pode ser supervisor de campo? Se sim, o conteúdo da supervisão de estágio deve 
estar presente no projeto pedagógico e nas disciplinas de área específica?

- O que as Residências estão produzindo em termos de trabalho de conclusão de curso? Os temas vêm contribuindo com a área, com o curso e com a atuação profissional?

- Problematizar a proposta de transformar a Residência em mestrado profissionalizante;

- O que podemos vislumbrar/direcionar a partir da privatização dos Hospitais Universitários via EBSERH?

- O fórum de residentes precisa ser um espaço de aglutinação de forças;

- Ultrapassar a lógica de treinamento em serviço e pensar a Residência como um espaço de formação;

- Formação em serviço é uma bandeira de luta histórica e deve ser garantida.

Um elemento importante destacado é a necessidade de articulação com as entidades organizativas da categoria para o enfrentamento desses desafios, no sentido de fortalecer nos Programas de Residência uma proposta de formação e trabalho em saúde condizente com o projeto formativo e ético-político do Serviço Social.

Dessa forma, entre as diversas contribuições que as entidades podem oferecer, destacaram-se: acompanhar o debate sobre as Residências; contribuir para a organização coletiva e articulação aos movimentos sociais na área da saúde; realizar debates e socialização de informações a respeito das experiências dos programas; fazer acompanhamento e imprimir um debate que qualifique a intervenção profissional nos espaços sócio-ocupacionais na área da saúde.

\section{REFERÊNCIAS}

ABEPSS/CEDEPSS. Diretrizes gerais para o curso de Serviço Social. Cadernos ABEPSS, São Paulo, n. 7, p. 58-76, 1997.

BRASIL. Decreto n. 7.082, de 27 de janeiro de 2010. 
. Resolução da comissão nacional de residência multiprofissional em saúde - CNRMS n. 2, de 13.04.2012.

CFESS. Política de educação permanente do conjunto CFESSCRESS. Brasília, 2012.

CORREIA, M. V. Controle social na saúde. In: MOTA, A et al. (Org.). Serviço Social e Saúde: formação e trabalho profissional. São Paulo: OPAS; OMS; Ministério da Saúde, 2006. p. 111-138. 
